\title{
INTRACRANIAL COMPLICATIONS OF LEUKAEMIA TREATED WITH INTRATHECAL AMETHOPTERIN*
}

\author{
BY \\ BERNARD M. LAURANCE \\ From the Derbyshire Children's Hospital, Derby
}

(RECEIVED FOR PUBLICATION APRIL 1, 1960; AMENDED OCTOBER 6, 1960)

Because the peripheral blood and bone marrow in acute leukaemia of childhood can be controlled temporarily by the anti-folic acid, the anti-purine and the steroid drugs, the prognosis of the disease has improved. However, none of these drugs prevents leukaemic infiltration of the brain, meninges or cranial nerves. Whiteside, Philips, Dargeon and Burchenal (1958) demonstrated that this was probably because an orally or parenterally administered drug did not penetrate the blood cerebrospinal fluid (C.S.F.) barrier in sufficient concentration to give a therapeutic level. However, when the antifolic acid drug, amethopterin (4-amino-N10 methyl pteroylglutamic acid) was given intrathecally, the C.S.F. levels were 30 to 100 times higher than those found after a massive single oral dose.

Treatment of these neurological complications of leukaemia with intrathecal amethopterin have been published in the American literature (Whiteside et al., 1958; Cramblett, 1959; Murphy, 1959). In the first child reported here the response to intrathecal therapy was quite dramatic. The report of a second child who had mild meningeal involvement is included because both this and the first child had swellings on the skull surface which were presumed to be leukaemic deposits and which disappeared after treatment. The report is intended primarily to stress the treatment of the intracranial complications of leukaemia, so that only brief reference is made to the general aspects of the disease.

\section{Case Reports}

Case 1. A girl of 2 years and 10 months was first seen in February, 1959. She was pale, had scattered purpura and bruises, generalized lymphadenopathy and an enlarged liver and spleen. No other abnormal signs were found. The haemoglobin was $38 \%(5.62 \mathrm{~g}$.), red blood cells $3,000,000 /$ c.mm., platelets $128,000 /$ c.mm., white blood cells 32,500/c.mm. of which $97 \%$ were lymphocytes and included some primitive cells.

* Based on a paper read to the Sheffield Paediatric Society, October, 1960.
The bone marrow was typical of acute leukaemia. After a blood transfusion she was treated over the next four months with 6-mercaptopurine supplemented by three short courses of prednisone. Thereafter her blood remained well controlled by the purine antagonist alone. From the start of her treatment she remained well in herself and only had 32 days in hospital during the first 10 months of her illness. She inexplicably developed a Cushing-like appearance although she had not had any prednisone for the previous four months. On December 16, 1959, she complained of ear-ache and was found to be blind in the right eye. The left ear drum was opaque and slightly reddened and there was bilateral papilloedema of approximately 1 dioptre, but no haemorrhages (Mr. Charles Bamford) (Fig. 1). Three swellings on the scalp were presumed to be leukaemic deposits. A skull radiograph showed separation of the sutures (Fig. 2) and the C.S.F., which was under normal pressure, contained 1,000 cells/c.mm., $99 \%$ of which were primitive; protein, $110 \mathrm{mg}$. \%; sugar, $49 \mathrm{mg}$. \%; chlorides, $662 \mathrm{mg}$. \%. The haemoglobin was $90 \%$ (13.3 g.), red blood cells 3,610,000/c.mm., white blood cells $1,700 /$ c.mm. (neutrophil series $60 \%$, lymphocyte series $40 \%$; no immature cells seen). Platelets 106,000 / c.mm. Two bone marrow specimens were poorly cellular, but contained $4 \%$ myeloblasts.

As there were presumed intracranial and skull deposits, and because the blood and marrow picture suggested a relapse of the leukaemia, therapy was changed on December 17, 1959, to oral amethopterin $2.5 \mathrm{mg}$. every other day. The blood picture had deteriorated by December 24 and so prednisone $10 \mathrm{mg}$. daily was added, but meanwhile, on December 18, amethopterin $10 \mathrm{mg}$. dissolved in $2 \mathrm{ml}$. of water and diluted with $8 \mathrm{ml}$. of C.S.F. was injected intrathecally. This was repeated on December 21 and 24, 1959, and on January 5, 1960. At each lumbar puncture the cell count had improved so that by January 12 there were only nine normal looking polymorphs and $25 \mathrm{mg}$. \% of protein. The serum uric acid on December 22 and 31 was 4.5 and $2.6 \mathrm{mg}$. respectively. Full vision had returned after the third intrathecal dose, and by January $6 \mathrm{Mr}$. Charles Bamford reported that the optic discs were entirely normal (Fig. 3). The skull deposits were no longer palpable, and the ear drum was now normal. A skull radiograph showed less separation of the sutures. 


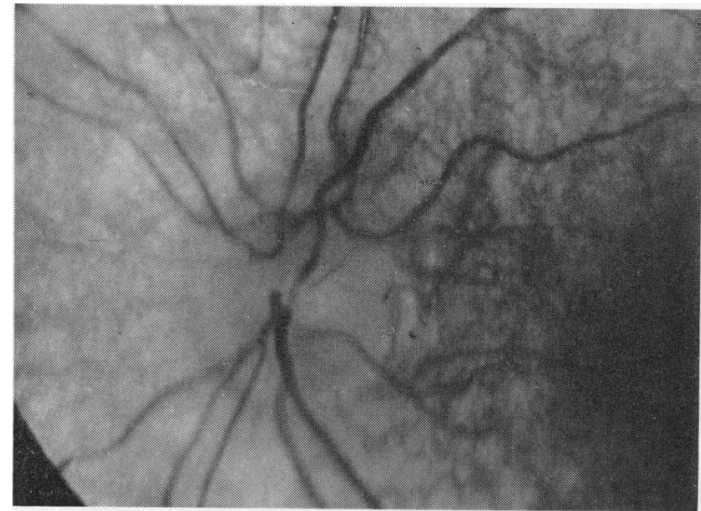

FIG. 1.

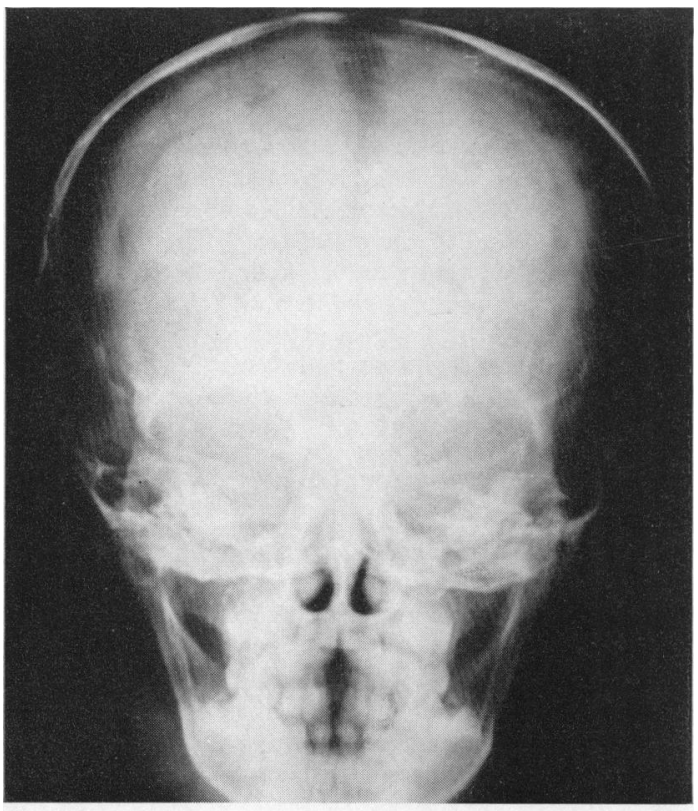

FIG. 3.

The child remained well but bilateral papilloedema was found at a routine examination in August, 1960. There was also another small swelling over the skull. The peripheral blood picture, the bone marrow and the skull radiograph were all normal, but the C.S.F. contained many primitive cells (Table and Fig. 4). The specimens for the above investigations were obtained under one anaesthetic, which was preceded by $50 \mathrm{mg}$. hydrocortisone intramuscularly as the child had had steroids previously. Intrathecal amethopterin $5 \mathrm{mg}$., diluted as before, was given at the time of this lumbar puncture and $10 \mathrm{mg}$. was given four days later and again four days after this. The Table shows how quickly the C.S.F. cleared. The skull deposit was no longer

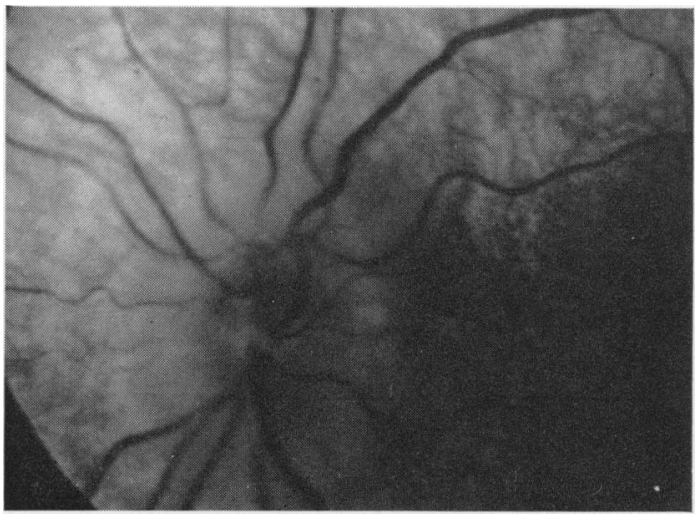

FIG. 2.

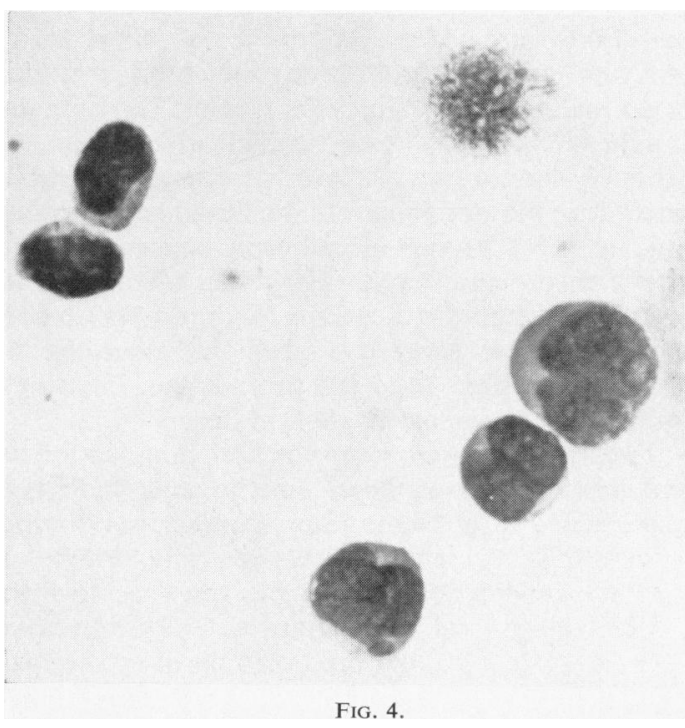

FIG. 1.-Case 1, the papilloedema before treatment (left disc). FIG. 2.-Case 1, separation of the sutures.

Fig. 3.-Case 1, the fundus 15 days later (left disc).

FIG. 4.-Case 1, lymphocytes in cerebrospinal fluid. $(\times 750$.)

palpable. Meanwhile the child had continued her oral amethopterin $2.5 \mathrm{mg}$. on alternate days, but daily blood counts showed that all elements were depressed. Eight days after the initial intrathecal dose, the haemoglobin was $70 \%(10 \cdot 3$ g. $)$, red cells $2,720,000 /$ c.mm., white cells $2,000 /$ c.mm. of which $49 \%$ were neutrophils, $45 \%$ lymphocytes and $9 \%$ monocytes; platelets were $26,000 /$ c.mm. She was too ill for bone marrow aspiration. The serum uric acid four days after the first dose of intrathecal amethopterin was $6.2 \mathrm{mg} . / 100 \mathrm{ml}$. Despite stopping the oral amethopterin and giving blood transfusions, citrovorum factor $5 \mathrm{mg}$. three times a day and large doses of prednisone, the blood picture 
TABLE

C.S.F. CHANGES AFTER INTRATHECAL AMETHOPTERIN

\begin{tabular}{|c|c|c|c|c|c|c|c|c|c|}
\hline \multirow[t]{2}{*}{ Date } & \multirow{2}{*}{$\begin{array}{c}\text { Intrathecal } \\
\text { Amethopterin } \\
\text { (mg.) }\end{array}$} & \multicolumn{5}{|c|}{ Cells } & \multirow{2}{*}{$\frac{\text { Sugar }}{\underset{(\%)}{\mathrm{mg}}}$} & \multirow{2}{*}{$\frac{\text { Protein }}{\underset{(\%)}{\mathrm{mg}}}$} & \multirow{2}{*}{$\begin{array}{c}\text { Chloride } \\
\mathrm{mEq} . / 1 .\end{array}$} \\
\hline & & Total & R.B.C. & $\begin{array}{c}\text { Blastocytes } \\
(\%)\end{array}$ & $\begin{array}{c}\text { Polymorphs } \\
(\%)\end{array}$ & $\begin{array}{l}\text { Lymphocytes } \\
(\%)\end{array}$ & & & \\
\hline August 11, & 5 & $2,115,000$ & - & 70 & - & 30 & 20 & 180 & 111 \\
\hline August 15, & 10 & 445 & 395 & 5 & 35 & 10 & 46 & 150 & 116 \\
\hline$\underset{1960}{\text { August } 19}$ & 10 & 33 & 17 & - & 16 & - & 42 & 100 & 112 \\
\hline
\end{tabular}

reflected a presumed total marrow aplasia and the child died 15 days after papilloedema had developed for the second time, eight months after it had been found on the first occasion and 18 months after the onset of her disease. Permission for autopsy was refused.

Case 2. A girl of $7 \frac{1}{2}$ years was first seen in October, 1958. Her paternal grandfather had died of leukaemia. Six months after she first attended hospital her mother died of malignant melanoma. The girl looked ill and pale and had moderately large glands in the left supraclavicular fossa, left axilla and in both groins. There was pain on abduction and flexion of the left hip, but there was full movement in this and all other joints. The spleen was considerably enlarged. The haemcglobin was $56 \%(8 \cdot 2$ g.), white blood cells $15,700 / \mathrm{c} . \mathrm{mm}$., of which $88 \%$ were primitive cells; platelets 114,000 / c.mm. The bone marrow appearances were typical of leukaemia. No deposits were visible radiologically in the hip or thigh.

Following a blood transfusion, she was treated with 6-mercaptopurine and prednisone for 27 days. Thereafter treatment was continued with the antipurine drug alone. She remained well and attended school regularly until January, 1960, 15 months after her first attendance at hospital, when she noticed a firm, painless 'lump' cn her head. Two weeks later, this was larger and there were two more present. No other abnormal signs were found. A skull radiograph was normal. Haemoglobin $112 \% \quad(16.6$ g.), W.B.C. 3,200/c.mm. (neutrophils $70 \%$, lymphocytes $30 \%$ ); platelets $141,000 / \mathrm{c} . \mathrm{mm}$. The C.S.F. was under normal pressure, and contained 26 'primitive' cells per c.mm. only; protein $15 \mathrm{mg}$. \%. Unfortunately the sugar content was not measured. Intrathecal amethopterin $10 \mathrm{mg}$. was given in the same dilution as for the first patient. Second and third doses were given four and three days later respectively. At the time of the third dose, the C.S.F. contained 11 normal looking lymphocytes per c.mm., protein $15 \%$, chlorides $120 \mathrm{mg}$. \% and sugar $57 \mathrm{mg}$. \%. The serum uric acid was $2.5 \mathrm{mg}$. \% six days after this third dose. The two smaller skull deposits had gone, and the large one was smaller. The child remained in good health. However, 13 days later, two fresh skull deposits had appeared, and in addition the remaining one had enlarged again to about its original size. The left tonsillar gland was also large and firm. The blood count remained satisfactory.
The C.S.F. contained only one normal lymphocyte, and the chemistry was normal. Therapy was changed to oral amethopterin and on this the child remained moderately well at home. By May, 1960, however, there was an obvious deterioration, although the skull deposits remained unaltered. Reintroduction of steroids in high dosage gave temporary benefit, but she died at the end of July, 22 months after her illness was first diagnosed.

At autopsy there were generalized petechial haemorrhages over the whole body. Leukaemic deposits were scattered throughout the brain, lungs, spleen and liver.

\section{Discussion}

As orally administered antimetabolite drugs such as 6-mercaptopurine and amethopterin control the peripheral blood and bone marrow, but not the intracranial manifestations of leukaemia, it is likely that these neurological complications will become commoner as survival from acute leukaemia becomes longer. It is therefore imperative to search for treatment for these complications.

It seems reasonable to assume that the neurological complications in the first child were the result of leukaemic infiltration of the brain, meninges or cranial nerves, and that the palpable masses in the skulls of both children were leukaemic deposits. It might be argued that the reintroduction of steroids in the first patient was the cause of her remarkable improvement, or that it was the result of a combination of the drug with the intrathecal amethopterin. However, it is well known that the neurological manifestations of leukaemia occur despite all oral treatment, so that it is probable that the intrathecal treatment was responsible for the resolution of these symptoms. That these remissions are temporary was noted by Whiteside et al. (1958) who found the effect to last for only four to six weeks in the four children they treated for presumed intracranial leukaemic infiltration. Nevertheless, one of the four patients reported by Cramblett (1959), and eight of the 23 patients reported by Murphy (1959) had a remission of intracranial complications of 
up to eight months. The last author considered that the best results were obtained in the patient with headache, increased intracranial pressure, papilloedema, vomiting, separation of the cranial sutures and a pleiocytosis of the cerebrospinal fluid; all the signs shown by the first child reported here who also survived for eight months after treatment of the first intracranial complications. The deposits on the skull of the first child disappeared completely and they diminished temporarily in the second. As this could only have been the result of the intrathecal amethopterin in the latter child, this was probably true also of the first. However, the remission was so brief in the second child that in view of the apparent improvement after intrathecal amethopterin this drug was given orally too. Presumably the drugs given intrathecally can reach skull deposits via the diploic veins which communicate with the meningeal veins.

The type of cells in the cerebrospinal fluid of both patients proved difficult to identify at first, but when seen on the second occasion in the first child they were easily recognized as lymphoblasts. The protein content of the fluid was high at first but fell as improvement occurred. On both occasions in the first patient the sugar content was low initially, which confirms the findings of other workers.

The number of intrathecal injections that should be given remains conjectural, but the average of the authors quoted seems to be three or four. Murphy (1959) gave 10 injections to one patient without harm. The dose quoted averaged $0.5 \mathrm{mg} . / \mathrm{kg}$. at three- or four-day intervals. In both the patients reported here this dose, given on three occasions, was sufficient to restore the C.S.F. to normal apart from the second relapse in the first child when the fluid was still not quite clear. Even on this occasion, there was a most remarkable improvement in the cell count after the first dose, i.e. a fall in four days from over $2,000,000$ white cells, $70 \%$ of which were lymphoblasts, to 50 cells of which only $5 \%$ were lymphoblasts. Of greater interest though was the apparent depression of all elements of this child's bone marrow after $15 \mathrm{mg}$. of amethopterin had been given intrathecally. Unfortunately the child was too ill and the platelet count too low to warrant a further bone marrow biopsy and this examination was not allowed after death. It is known that a small amount of amethopterin given orally crosses the blood brain barrier, but it must remain hypothetical whether the intrathecal amethopterin crossed back to the blood from the cerebrospinal fluid through a normal barrier or one that was affected by the disease. Alternatively, the marrow relapsed a week after it had been shown to be normal.

It does seem, though, that, frequent marrow biopsies are important during intrathecal treatment. It is difficult to assess whether oral amethopterin should be given if 6-mercaptopurine is still controlling the blood picture as it was in the second patient. Certainly frequent examination of the fundi of children under treatment for this disease is obviously essential.

When a large amount of leukaemic tissue is destroyed by antimetabolites in a short time, hyperuricaemia has been reported. In these two patients the serum uric acid levels were normal.

\section{Summary}

Two children with acute leukaemia were treated with 6-mercaptopurine for 10 and 15 months respectively before they developed swellings on the skull which were presumed to be leukaemic deposits. The first child also had neurological signs and both had changes in the C.S.F. suggestive of intracranial deposits.

After treatment with intrathecal amethopterin, the neurological signs disappeared and the C.S.F. cleared. In one child these signs reappeared eight months later, but although the C.S.F. responded to intrathecal treatment, the child died. The swellings also disappeared in the first patient and diminished temporarily in the second. The reason for this disappearance is discussed. Stress is laid on the importance of frequent examination of the fundi of patients with this disease.

I wish to thank Dr. C. W. P. Bradfield for the radiograph reports and Mr. W. Spink, F.B.O.A.(Hons.), Senior Ophthalmic Optician to the Derbyshire Royal Infirmary, for the fundus photographs (originally in colour) of Case 1. Dr. G. R. Osborn and Dr. B. Leonard kindly reported on the C.S.F. and haematology findings and gave much valuable advice. It is a pleasure to acknowledge the prompt gift of the intrathecal amethopterin (methotrexate) from Dr. Ruth Porter, M.R.C.P., of Lederle Laboratories, London.

\section{REFERENCES}

Cramblett, H. G. (1959). Recognition and treatment of intracranial manifestations of leukaemia. A.M.A. J. Dis. Child., 97, 805 .

Murphy, M. L. (1959). Leukemia and lymphoma in children. Pediat. Clin. N. Amer., 6, 611.

Whiteside, J. A., Philips, F. S., Dargeon, H. W., Burchenal, J. H. (1958). Intrathecal amethopterin in neurological manifestations of leukemia. A.M.A. Arch. intern. Med., 101, 279. 